\title{
PSICOLOGIA AmBIENTAL E POLÍTICA AMBIENTAL: ESTRATÉGIAS DE CONSTRUÇÃO DO FUTURO
}

\author{
Jean-Paul Thibaud ${ }^{1}$ \\ Escola de Arquitetura de Grenoble
}

\begin{abstract}
O autor questiona o entendimento de "ambiente" e, como conseqüência, aponta que a Psicologia Ambiental deve tratar de três problemas principais e inter-relacionados: primeiro, levar em conta as dimensões sensoriais do ambiente; segundo, ampliar o escopo do ambiente retornando à própria base da experiência cotidiana; terceiro, elaborar métodos contextuais e descritivos que possibilitem a interdisciplinaridade. Propõe, portanto, a necessidade de uma mudança de paradigma.
\end{abstract}

Descritores: Psicologia ambiental. Política ambiental. Ambientes urbanos. Modo de vida.

\begin{abstract}
Drimeiramente, gostaria de agradecer aos organizadores deste Simpósio 1 por ter me convidado ao Brasil. Estou feliz e honrado de fazer parte deste encontro muito interessante e espero que a minha contribuição estará à altura da importância das questões que estão sendo discutidas durante esta semana.
\end{abstract}

Antes de tentar responder às três questões, permitam-me que me apresente e conte a vocês de que ponto de vista vou lhes falar. Não sou um psi-

1 Sociólogo, diretor adjunto e pesquisador do CRESSON - Centro de Pesquisa sobre o espaço Sonoro e o Ambiente Urbano. Coordenador de pesquisas e estudos de "Percepção comum das ambiâncias no meio urbano". Endereço eletrônico: JeanPaul.Thibaud@grenoble.archi.fr 
cólogo e, certamente, não sou em especialista em Psicologia Ambiental (PA). Embora eu tenha muito interesse na PA, minha competência é a de um sociólogo que faz pesquisa sobre o ambiente urbano. Mais precisamente, pertenço a um laboratório francês de pesquisas que trabalha sobre questões de percepção situada, relações sociais, ambientes sensoriais usuais e desenho urbano. Estou acostumado a trabalhar com arquitetos e engenheiros. Meu campo principal de pesquisa se relaciona a lugares urbanos públicos. Tento entender melhor como os moradores da cidade experienciam, percebem e usam os lugares públicos.

De um certo modo, o que vocês irão escutar é a reflexão de um outsider, no sentido de que, se uso alguns resultados da PA, eu mesmo não venho desta disciplina científica. Pensei que tinha de contar a vocês isto de modo que vocês possam compreender o que tenho a dizer com respeito às três questões que pediram que respondesse.

Deixem-me começar com a primeira questão: Qual é o papel da PA na definição e implementação da Política Ambiental?

Parece que tal questão é muito complicada e ardilosa. Pressupõe que a PA pode ser considerada um campo unificado e coerente de pesquisa. Do mesmo modo, pressupõe que a Política Ambiental pode ser considerada um campo unificado e coerente de ação. Talvez seja necessário usar o plural e introduzir a diversidade em ambos os domínios a fim de ser capaz de responder a esta questão. Por um lado, a PA envolve vários tipos de métodos, de bases teóricas e de resultados empíricos, que podem ser mais ou menos compatíveis e efetivos com relação à Política Ambiental. Deste ponto de vista, a questão teria de ser reformulada: Quais são as abordagens da PA que são capazes de ter um papel na definição e implementação da Política Ambiental? Não vou agora responder a esta questão mas penso que é uma das que deveríamos tentar discutir juntos.

Por outro lado, a Política Ambiental envolve várias escalas de aplicação que são mais ou menos abertas à contribuição da PA. Quando nos referimos à Política Ambiental, estamos nos referindo ao seu nível internacional, nacional, regional ou local? Estamos falando de preocupações compartilha- 
das internacionais - como, por exemplo, o problema do efeito estufa - ou estamos falando de níveis mais micro e situados, tais como o planejamento de um lugar? Obviamente, essas são questões diferentes. Aqui, novamente, temos de reformular a questão original: Que tipo de Política Ambiental pode estar interessada e integrar o que a PA tem a oferecer? Obviamente, esta segunda questão tem de ser articulada com a primeira. Para resumir, penso que deveríamos tentar esclarecer, talvez distinguir e identificar, as principais tendências em jogo tanto na PA quanto na Política Ambiental. Assim, ao invés de começar com uma questão muito ampla, poderíamos tentar ser mais específicos. Por exemplo, perguntando: Que tipo de PA e para que questões de Política Ambiental? Este era o primeiro argumento que eu queria destacar.

Um outro modo de responder à questão é focalizar o próprio termo "Ambiente". O que queremos dizer por Ambiente? Enfatizarei apenas um argumento principal. Sugiro distinguir entre o ambiente que é perceptível e aquele que não é perceptível.

Na primeira categoria, refiro-me ao ambiente que podemos ver, escutar, cheirar ou tocar, que podemos chamar de "ambiente sensorial". Tal ambiente é caracterizado pelo fato de que ele se relaciona diretamente à experiência e ao comportamento de pessoas na sua vida cotidiana. Se focalizarmos o ambiente sensorial em termos de conforto ou de sociabilidade, de estética ou de informação, a questão é proporcionar uma melhor compreensão das relações entre os moradores e o ambiente construído. Em outras palavras, a PA pode ajudar arquitetos e planejadores urbanos no projeto de edifícios e lugares. Deste ponto de vista, a fim de definir o papel da PA na definição e implementação da Política Ambiental, temos de introduzir um terceiro termo, que poderíamos de chamar de "Projeto (Design) Ambiental". Este tipo de prática pode ser situada entre a PA e a Política Ambiental. Os "projetistas" ambientais dependem da PA tanto para refletir sobre a complexidade do processo de projetar quanto para integrar, em sua proposta final, as requis ições e recomendações da Política Ambiental. De um certo modo, eles desempenham um papel crucial na interface entre a Psicologia Ambiental e a Política Ambiental. 
A segunda categoria de ambiente é aquele que não é diretamente perceptível, que poderíamos chamar de "ambiente extra-sensorial". Por exemplo, alguns produtos químicos presentes na atmosfera podem ser perigosos para a nossa saúde, mesmo que não possamos necessariamente sentir o seu cheiro. De igual modo, a água pode estar poluída mesmo se nós não identificarmos isto necessariamente pelo seu gosto. Tais fenômenos revelam que o ambiente não é redutível a seus componentes perceptíveis. Deste ponto de vista, a Política Ambiental depende essencialmente do conhecimento médico e biológico. Está muito relacionada à Saúde Pública e envolve questões socioeconômicas de larga escala.

Esta distinção entre "ambiente extra-sensorial" e "sensorial" me parece crucial no questionamento das relações entre a PA e a Política Ambiental. Minha opinião é de que deveríamos focalizar no modo como a PA lida com a percepção usual.

Este argumento me leva à segunda questão: De que modo a Psicologia Ambiental determina estratégias para a construção do futuro? A maior parte do tempo, a Política Ambiental que lida com o ambiente sensorial envolve uma abordagem normativa, quantitativa e determinista. A primeira, e quase única, base da Política Ambiental são os sina is físicos. Supõe-se que os problemas ambientais podem ser resolvidos controlando e regulando os inputs do ambiente. Tudo acontece como se as pessoas fossem recipientes passivos do ambiente físico. Penso que a PA tem muito a dizer sobre este modo de pensar. Poderia ajudar a renovar esta abordagem de duas maneiras principais.

A primeira maneira seria proporcionar uma mudança de paradigma. A PA pode ajudar a destacar os pressupostos subjacentes encravados na tendência principal da Política Ambiental. Colocando de modo sucinto: a dimensão humana do ambiente vivido é freqüentemente super-simplificada. Três argumentos básicos têm de ser contestados e superados. O principal deles, o de que as pessoas não podem ser reduzidas a sujeitos médios idênticos entre si. Elas percebem e agem diferentemente dependendo da situação em que estão envolvidas, dependendo também de seu background social e 
cultural. Assim, temos de manter a diversidade das relações entre as pessoas e os seus entornos. Em segundo lugar, as pessoas não reagem passivamente ao ambiente. Atuam sobre ele, configuram-no e dão significado a ele. Em outras palavras, as pessoas não são "culturalmente ignorantes". Elas são atores competentes que usam várias habilidades e valores a fim de lidar com o ambiente. Em terceiro lugar, as pessoas não são sujeitos isolados. Não estão trancafiadas em sua própria subjetividade ou separadas umas das outras ao lidar com o ambiente. O ambiente é tanto uma construção social quanto um meio para a interação social. Ele não pode ser abordado de um ponto de vista atomístico ou solipcista. Para resumir este primeiro ponto, a PA pode revelar a complexidade das relações entre as pessoas e o seu entorno considerando as pessoas verdadeiramente como atores envolvidos, sujeitos competentes e seres humanos sociais. Ao invés de superestimar a dimensão física do ambiente, é preferível desenvolver novos modelos de inteligibilidade do ambiente que melhor articulem o físico com o social, o quantiativo com o qualitativo. Tal tarefa supõe uma mudança de paradigma: de um modelo "baseado nos estímulos" para um modelo "baseado na experiência".

$\mathrm{O}$ segundo ponto em termos prospectivos seria desenvolver um novo campo de pesquisa. Em geral, a Política Ambiental focaliza situações extremas, excepcionais ou limites. Obviamente, há boas razões para isto. É uma prioridade resolver problemas mais urgentes e dramáticos. Contudo, tal foco é somente uma pequena parte do quadro total, somente o aspecto mais visível das questões ambientais. É minha opinião que a PA deveria ajudar a ampliar o escopo da Política Ambiental ressaltando o que subjaz sob o iceberg. E sobre o ambiente cotidiano? Como nos movemos de um ambiente problemático para um hospitaleiro? Como é possível prestar contas quanto ao modo como as pessoas lidam com o ambiente em sua vida diária? O que podemos aprender das situações mais comuns e usuais? Parece que tais questões valem a pena ser exploradas e poderiam proporcionar novas perspectivas referentes às questões ambientais. Eu disse anteriormente que deveríamos tentar substituir o modelo "baseado nos estímulos" por um modelo "baseado na experiência". Acrescento, agora, que este novo modelo poderia 
ser aplicado à vida cotidiana. Afinal, o ambiente da vida cotidiana é mais significativo do que parece. Ele é tanto a espinha dorsal quanto o fundo sobre os quais construímos a própria base de nosso modo de ser-no-mundo.

De um certo modo, já comecei a responder à terceira questão: Em que direção a PA deve se desenvolver? Quais desenvolvimentos devem ser encorajados? Deixem-me apenas acrescentar uma sugestão a mais. O principal desafio para as ciências atualmente é trabalhar em seu próprios limites e estabelecer elos com as outras disciplinas. Ao invés de fechar a PA em si própria, é mais importante abri-la para os vários campos de pesquisa. Isto não significa que a PA deveria se amalgamar e perder a sua especificidade. Ao contrário, significa que a PA está suficientemente desenvolvida para se envolver em um programa interdisciplinar. Para ser mais preciso, temos de distinguir multidisciplinaridade de interdisciplinaridade. Multidisciplinaridade é uma opção primeira e, certamente, a mais fácil. Requer um objeto compartilhado e comum de pesquisa que possa ser abordado de vários pontos de vista. Por exemplo, o ambiente sensorial pode ser analisado de uma perspectiva física pela mensuração de sinais acústicos ou luminosos. Pode também ser descrito de uma perspectiva arquitetônica pela caracterização dos efeitos do espaço construído sobre a sonoridade ou sobre a luminosidade do lugar. Pode, finalmente, ser observado de uma perspectiva psicológica e sociológica levando em conta como as pessoas percebem o seu ambiente e interagem com ele. Tal processo pluralista é um primeiro passo para colocar um problema em perspectiva e reconhecer a complexidade do ambiente. Contudo, seu limite é que ele justapõe vários conjuntos de conhecimentos sem ser realmente capaz de articulá-los. Por outro lado, a interdisciplinaridade é mais exigente e ambiciosa. Não somente requer um objeto compartilhado de pesquisa como também uma linguagem comum entre as disciplinas científicas em jogo. Deste ponto de vista, a interdisciplinaridade envolve instrumentos metodológicos que não se afiliam a uma única abordagem mas, ao contrário, são transversais. Por transversal, quero dizer instrumentos e categorias que possibilitem circular entre várias disciplinas científicas. Parece-me que um dos meios de adquirir tal meta seria questionar o ambiente sensorial de um ponto de vista fenomenológico. Ao invés de focalizar os 
efeitos do ambiente sobre os comportamentos das pessoas, poderíamos tentar compreender melhor a maneira como o ambiente aparece para nós através de fenômenos sensoriais muito básicos. Em outras palavras, antes de tentar explicar alguma coisa, deveríamos tentar elaborar instrumentos e métodos descritivos. A descrição me parece a primeira questão a ser focalizada a fim de se desenvolver uma abordagem interdisciplinar. O desafio é elaborar um vocabulário, e talvez uma gramática, que pudesse ser partilhada pelos vários campos de pesquisa que com o ambiente humano.

Em resumo, penso que a Psicologia Ambiental deve tratar de três problemas principais e inter-relacionados: primeiro de tudo, levar em conta as dimensões sensoriais do ambiente; em segundo lugar, ampliar o escopo do ambiente retornando à própria base da experiência cotidiana; em terceiro, elaborar métodos contextuais e descritivos que possibilitem a interdisciplinaridade.

Thibaud, J-P. (2005). Environmental psychology and environmental policy: Strategies of construction of the future. Psicologia USP, 16(1/2), 205212.

\begin{abstract}
The author questions the understanding of "environment" and, consequently, argues that Environmental Psychology must deal with three main interrelated problems: first, it must take into account the sensory dimensions of the environment; second, it must broaden the scope of environment, returning to the basis of daily experience; third, it must elaborate contextual and descriptive methods that make interdisciplinarity possible. Therefore, he proposes the need for a change in paradigm.
\end{abstract}

Index terms: Environmental psychology. Environmental policy. Urban environments. Lifestyle.

Thibaud, J-P. (2005). Psychologie de l'environnement et politique de l'environnement: strategies de construction du futur. Psicologia USP, $16(1 / 2), 205-212$. 
Résumé: L'auteur met en cause l'entendement de "l'environnement" et signale, en conséquence, que la Psychologie de l'Environnement devrait traiter trois problèmes principaux et étroitement reliés entre eux: premièrement, tenir compte des dimensions sensorielles de l'environnement; deuxièmement, augmenter la portée de l'environnement revenant à la propre base de l'expérience quotidienne; troisièmement, élaborer des méthodes contextuelles et descriptives qui permettent l'interdisciplinarité. Il propose, donc, la nécessité d'un changement de paradigme.

Mots-clés: Psychologie de l'environnement. Politique de l'environnement. Environnement urbain. Mode de vie.

Recebido em 5.04.2004 Aceito em 7.03.2005 